\title{
INFLUÊNCIA DA CONTAGEM DE CÉLULAS SOMÁTICAS NA COMPOSIÇÃO QUÍMICA DO LEITE REFRIGERADO DA REGIÃO SUDOESTE DE GOIÁS
}

\section{Influence of somatic cell count on chemical composition of milk refrigerated of Goiás southwest region}

\author{
Thiago Soares Carvalhol, Marco Antônio Pereira da Silva ${ }^{l *}$, \\ Rafaella Belchior Brasil ${ }^{l}$, Karen Martins Leãol, Marcos Roberto da Silva ${ }^{l}$, \\ Letícia Aparecida de Morais ${ }^{I}$
}

\begin{abstract}
RESUMO
O objetivo deste trabalho foi avaliar a influência da contagem de células somáticas (CCS) na composição centesimal e contagem bacteriana total (CBT) do leite cru refrigerado coletado no Sudoeste Goiano. Foram coletados dados de composição centesimal, CCS e CBT de laudos emitidos pelo Laboratório de Qualidade do Leite (LQL) do Centro de Pesquisa em Alimentos (CPA) da Escola de Veterinária e Zootecnia da Universidade Federal de Goiás. Os dados foram agrupados de acordo com a CCS em seis intervalos, variando de $\leq 200.000 \mathrm{CS} / \mathrm{mL}$ a $\geq 1.001000 \mathrm{CS} / \mathrm{mL}$, sendo o intervalo 1 com 530 amostras, intervalo 2 com 725 amostras, intervalo 3 com 469 amostras, intervalo 4 com 302 amostras, intervalo 5 com 183 amostras e intervalo 6 com 362 amostras. A CCS acima de $1001 \mathrm{mil} \mathrm{CS} / \mathrm{mL}$ refletiu no aumento do teor de gordura do leite. O maior teor de proteína e extrato seco total (EST) podem ser associados a uma baixa CCS, sendo que o teor de lactose e extrato seco desengordurado (ESD) diminuem com o aumento da CCS. A composição centesimal do leite a granel coletado no Sudoeste Goiano independente do aumento da CCS. A CCS resultou em valores acima dos limites mínimos estabelecidos pela legislação brasileira. A CCS abaixo de $200 \mathrm{mil} \mathrm{CS} / \mathrm{mL}$ está associada a uma menor CBT.
\end{abstract}

Palavras-chave: qualidade microbiológica; qualidade leite; sudoeste goiano.

1 Instituto Federal Goiano, Campus Rio Verde, Av. Sul Goiânia, km 1, Zona Rural, 75901-970, Rio Verde, GO, Brasil. E-mail: marcotonyrv@yahoo.com.br.

* Autor para correspondência.

Recebido / Received: 31/07/2015

Aprovado / Approved: 22/02/2016 


\begin{abstract}
The objective was to this study of evaluate the influence of chemical composition on somatic cell count and total bacterial count cool and draw milk collected in the Southwest Goiás. Data were collected for chemical composition, SCC and TBC of reports issued by the Laboratory of Milk Quality (LQL) of the Center for Food Research (CPA) School of Veterinary and Animal Science, Federal University of Goiás, in Brazil. Data were grouped according to the SCC at six interval ranging $\leq 200,000 \mathrm{SC} / \mathrm{mL}$ at $\geq 1.001000 \mathrm{SC} / \mathrm{ml}$, with the range 1 to 530 samples, 2 to 725 samples, 3 to 469 samples, 4 to 302 samples, 5 to 183 samples and 6 with 362 samples. SCC above 1,001,000 SC/mL reflected in the increase of the milk fat content. The higher content of protein and total dry stratum maybe associated with a low SCC, and the lactose contente of Stratum solids non-fat decreases with the increase in SCC. The chemical composition of bulk milk collected in the Southwest Goiás independente of SCC resulted in increased values above the minimum limits established by Brazilian legislation. SCC below $200,000 \mathrm{SC} / \mathrm{mL}$ is associated with a lower TBC.
\end{abstract}

Keywords: microbiological quality; milk quality; southwest Goiás.

\section{INTRODUÇÃO}

A atividade leiteira é praticada em todo o território brasileiro, e por isto representa um dos segmentos mais importantes do agronegócio. Atingir a eficiência e a rentabilidade tem sido o grande objetivo nos diversos setores da produção animal, sobretudo no que diz respeito às propriedades leiteiras (RODRIGUES, 2008).

A melhoria na qualidade do leite no Brasil deve-se ao aumento da demanda por matéria-prima de qualidade pela indústria, que necessita de leite com boas características sensoriais, físico-químicas e microbiológicas para fabricação de produtos lácteos, tendo em vista que os consumidores estão cada vez mais exigentes.

A composição e a qualidade microbiológica do leite são dois itens de grande importância para bons resultados econômicos, tanto nas propriedades leiteiras como nas indústrias de laticínios. A inserção do setor produtivo brasileiro de leite e derivados na economia internacional globalizada tem levado à necessidade de modernização e de aumento de competitividade por parte do setor (ALVES, 2006).

Visando estabelecer padrões de qua lidade do leite cru refrigerado, o Governo Federal, determinou valores mínimos para teores de gordura, proteína, extrato seco total e extrato seco desengordurado de $3,0 \% ; 2,9 \%$; $11,40 \%$ e $8,40 \%$ respectivamente, e contagem máxima de células somáticas (CCS) de $500 \mathrm{mil} \mathrm{CS} / \mathrm{mL}$ e contagem bacteriana total (CBT) de $300 \mathrm{mil} \mathrm{UFC/} \mathrm{mL} \mathrm{(BRASIL,} \mathrm{2011).}$

A alta CCS altera a composição físicoquímica do leite, diminuindo os rendimentos dos produtos lácteos, causando, portanto, prejuízos à indústria. Além disso, a CCS é de grande importância na avaliação do nível de mastite subclínica, na estimativa das perdas de produção do leite e na indicação da qualidade do leite produzido na fazenda (SANTOS et al., 2012).

A CBT tem sido usada como uma ferramenta para monitorar a qualidade do leite. Para evitar altas contagens é preciso trabalhar com higiene e refrigerar o leite o mais rápido possível após a ordenha, mantendo refrigerado na propriedade, por até 48 horas 
(DÜRR, 2005). Em seguida o leite deverá ser transportado em tanques isotérmicos até a indústria.

Sabendo que a qualidade do leite pode ser afetada por inúmeros fatores, o presente estudo teve como objetivo avaliar a influência da CCS do leite cru refrigerado na composição centesimal e CBT do leite coletado no Sudoeste Goiano.

\section{MATERIAL E MÉTODOS}

O presente trabalho foi realizado por meio da coleta de dados da composição centesimal, CCS e CBT de laudos emitidos pelo Laboratório de Qualidade do Leite (LQL) do Centro de Pesquisa em Alimentos (CPA) da Escola de Veterinária e Zootecnia da Universidade Federal de Goiás.

Os laudos referem-se a amostras de leite cru refrigerado coletadas na região $\mathrm{Su}-$ doeste de Goiás, no período de janeiro de 2008 a maio de 2011. Foram coletados 2.571 laudos referentes a avaliação da composição centesimal, CCS e CBT de amostras de leite cru refrigerado da região do Sudoeste Goiano.

Os dados foram agrupados de acordo com a CCS em seis intervalos (de 1 a 6) conforme mostra a Tabela 1 .

Tabela 1 - Intervalos estabelecidos da contagem de células somáticas (CCS) e quantidade de amostras de leite cru refrigerado coletadas na região do Sudoeste Goiano

\begin{tabular}{ccc}
\hline Intervalos & $\begin{array}{c}\text { CCS } \\
\left(\mathrm{x} 10^{3} \mathrm{CS} / \mathrm{mL}\right)\end{array}$ & $\begin{array}{c}\text { Número } \\
\text { amostras }\end{array}$ \\
\hline 1 & $\leq 200$ & 530 \\
2 & $201-400$ & 725 \\
3 & $401-600$ & 469 \\
4 & $601-800$ & 302 \\
5 & $801-1000$ & 183 \\
6 & $\geq 1001$ & 362 \\
\hline Total de amostras & 2.571 \\
\hline
\end{tabular}

Procedeu-se à análise de variância, sendo os fatores analisados: gordura, proteína, lactose, extrato seco total (EST), extrato seco desengordurado (ESD) e contagem de bactéria total (CBT) em função dos intervalos apresentados na Tabela 1. Para os valores da CBT, devido à falta de distribuição normal, os dados foram transformados, utilizando-se a função logarítmica do programa Excel ${ }^{\circledR}$.

Neste estudo foi utilizado o delineamento em blocos casualizados (DBC). O teste estatístico utilizado foi o Scott-Knott, a $5 \%$ de significância, utilizando-se o software SISVAR (FERREIRA, 2000).

\section{RESULTADOS E DISCUSSÃO}

Os valores médios dos teores de gordura, proteína, lactose, EST, ESD e CBT de acordo com os intervalos da CCS utilizados, encontram-se na Tabela 2.

O teor de gordura do leite cru refrigerado diferiu significativamente apenas nas amostras do intervalo 6 (CCS acima de $1.001 \mathrm{mil} \mathrm{CS} / \mathrm{mL}$ ) quando comparadas aos demais intervalos. A média das amostras que apresentaram diferença significativa foi de $3,82 \%$ de gordura, enquanto na CCS abaixo de $1000 \mathrm{mil} \mathrm{CS} / \mathrm{mL}$ o teor de gordura ficou abaixo de $3,72 \%$.

Os resultados de gordura do presente estudo foram maiores que os encontrados por Coelho et al. (2014), na região de Goiânia (GO), que relataram 3,51\% de gordura para o leite cru refrigerado. Ambos os estudos indicaram que conforme a CCS aumenta, também eleva-se o teor de gordura. $\mathrm{O}$ aumento no teor de gordura do leite também pode ser associado à alimentação do rebanho, uma vez que dietas com maior porcentagem de volumoso refletem no aumento da gordura do leite.

O teor de proteína bruta do intervalo 2 diferiu significativamente, quando comparado aos demais intervalos, sendo que a 
média foi de $3,30 \%$ e nos demais intervalos o teor proteico ficou abaixo de $3,27 \%$. Os valores de proteína obtidos no intervalo 2 são inferiores aos resultados encontrados por Coelho et al. (2014) que encontraram média de $3,38 \%$ de proteína. Na literatura temos resultados diferentes ao do presente estudo, como o obtido por Pereira et al. (1999), que encontraram concentração de proteína de 3,34\% no leite cru refrigerado com CCS acima de $280 \mathrm{mil} \mathrm{CS} / \mathrm{mL}$. Bueno et al. (2005) relatam uma diminuição nos teores de proteína no leite cru refrigerado conforme ocorre o aumento da CCS.

Variações nos teores de proteínas são determinantes no rendimento industrial da fabricação de queijos e de outros produtos lácteos dependentes de concentrações adequadas de caseína na matéria prima (LINDMARKMANSSON et al., 2003).

Os teores de lactose no leite cru refrigerado apresentam diferença significativa para praticamente todos os intervalos estudados, sendo que no intervalo 1 (CCS $\leq$ $200 \mathrm{mil} \mathrm{CS} / \mathrm{mL}$ ) foi observada a maior média $(4,60 \%)$. À medida que aumenta a CCS observa-se a diminuição nos teores de lactose, sendo que no intervalo $6(\mathrm{CCS} \geq 1001 \mathrm{mil} \mathrm{CS} / \mathrm{mL})$ verificou-se menor média de lactose $(4,39 \%)$.

Santos et al. (2008) estudou os efeitos do tempo de armazenagem sobre a composição centesimal do leite cru refrigerado no Sudoeste Goiano e verificou que o teor de lactose foi de 4,37\% no leite armazenado por até 72 horas. Em estudo semelhante ao presente trabalho, Bueno et al. (2005), encontraram a mesma média de lactose $(4,60 \%)$ para o intervalo $1(\mathrm{CCS} \leq$ a $200 \mathrm{mil} \mathrm{CS} / \mathrm{mL})$.

Segundo Schäellibaum (2000), o teor de lactose do leite tende a baixar com o aumento da CCS. Ponce; Hernández (2001) relataram que as concentrações de lactose reduzem na etapa final da lactação e também nos quadros de mastite.

Para os teores de EST houve diferença significativa $(\mathrm{P}<0,05)$, sendo que os interva$\operatorname{los} 1,2$ e 6 apresentaram maiores valores (12,48\%, $12,48 \%$ e $12,47 \%$ respectivamente). Os maiores teores de proteína e lactose dos intervalos 1 e 2 no leite foram os responsáveis por essas diferenças significativas no EST (Tabela 1), enquanto para o intervalo 6, o maior teor de gordura foi responsável pela diferença significativa.

Médias de EST superiores as encontradas no presente trabalho foram observadas

Tabela 2 - Composição centesimal* e CBT** em função dos intervalos da CCS do leite cru refrigerado da região Sudoeste de Goiás

\begin{tabular}{ccccccc}
\hline Intervalos & Gordura & Proteína & Lactose & EST & ESD & CBT \\
\hline 1 & $3,63^{\mathrm{b}}$ & $3,27^{\mathrm{b}}$ & $4,60^{\mathrm{a}}$ & $12,48^{\mathrm{a}}$ & $8,85^{\mathrm{a}}$ & $1.054^{\mathrm{a}}$ \\
2 & $3,67^{\mathrm{b}}$ & $3,30^{\mathrm{a}}$ & $4,54^{\mathrm{b}}$ & $12,48^{\mathrm{a}}$ & $8,81^{\mathrm{a}}$ & $1.702^{\mathrm{b}}$ \\
3 & $3,68^{\mathrm{b}}$ & $3,25^{\mathrm{b}}$ & $4,49^{\mathrm{c}}$ & $12,39^{\mathrm{b}}$ & $8,71^{\mathrm{b}}$ & $1.898^{\mathrm{b}}$ \\
4 & $3,67^{\mathrm{b}}$ & $3,25^{\mathrm{b}}$ & $4,47^{\mathrm{c}}$ & $12,36^{\mathrm{b}}$ & $8,68^{\mathrm{b}}$ & $1.470^{\mathrm{b}}$ \\
5 & $3,72^{\mathrm{b}}$ & $3,25^{\mathrm{b}}$ & $4,45^{\mathrm{d}}$ & $12,38^{\mathrm{b}}$ & $8,66^{\mathrm{b}}$ & $1.607^{\mathrm{b}}$ \\
6 & $3,82^{\mathrm{a}}$ & $3,26^{\mathrm{b}}$ & $4,39^{\mathrm{e}}$ & $12,47^{\mathrm{a}}$ & $8,62^{\mathrm{c}}$ & $1.455^{\mathrm{b}}$ \\
$\mathrm{CV}^{* * *}(\%)$ & 13,57 & 6,95 & 3,67 & 5,26 & 3,42 & 38,02 \\
\hline
\end{tabular}

* Letras diferentes na mesma coluna indicam diferença significativa $(\mathrm{P}<0,05)$, segundo teste de Scott-Knott a $5 \%$ de significância.

** Composição centesimal expressa em porcentagem (\%) e a CBT expresso em x $10^{3} \mathrm{UFC} / \mathrm{mL}$.

*** CV $=$ Coeficiente de Variação. 
por Bueno et al. (2005) que verificaram média de $12,61 \%$ de EST. Baggio; Montanhini (2014) avaliaram a qualidade do leite no norte do Paraná e observaram média inferior de $12,13 \%$ para EST.

Os resultados do ESD diferiram estatisticamente $(\mathrm{P}<0,05)$ entre os intervalos estudados, sendo que no intervalo 1 (CCS $\leq$ $200 \mathrm{mil} \mathrm{CS} / \mathrm{mL}$ ) foi verificada a maior média $(8,85 \%)$ e no intervalo 6 (CCS $>1001 \mathrm{mil}$ $\mathrm{CS} / \mathrm{mL}$ ) foi obtida média de $8,62 \%$.

Valor de ESD igual ao observado no intervalo 6 do presente estudo foi relatado por Santos et al. (2012), no leite armazenado por 48 horas. No entanto, valor inferior de ESD foi observado por Rosa et al. (2012) que verificou média de $8,49 \%$ no leite cru refrigerado em tanques de expansão no Rio Grande do Sul.

Observou-se que as variações que ocorrem nos ESD e EST são semelhantes, ou seja, as variações acontecem pelo decréscimo de proteína e lactose conforme ocorre o aumento da CCS no leite cru refrigerado.

A CBT diferiu significativamente, no intervalo 1 (CCS $\leq 200 \mathrm{mil} \mathrm{CS} / \mathrm{mL}$ ) indicando que há efeito da CCS sobre a CBT do leite cru refrigerado, ou seja, a higiene da ordenha resulta em baixa $\mathrm{CBT}$ e consequente redução da CCS.

Resultados semelhantes foram observados por Martins et al. (2008), que verificaram que em trinta tanques de expansão, nove estavam com CBT acima de $10^{6} \mathrm{UFC} / \mathrm{mL}$. Santos et al. (2012) avaliando leite na mesma região do Sudoeste Goiano verificou média de $5,3 \times 10^{5} \mathrm{UFC} / \mathrm{mL}$. Conforme Ramires et al. (2009), nem sempre se pode relacionar a CBT com a CCS, uma vez que os microrganismos têm alta capacidade de reprodução, podendo ser um reflexo de quadros de mastites ou de baixa qualidade da água utilizada para higienização de utensílios ou falhas no sistema de refrigeração do leite.

Os valores da CBT observados no presente trabalho são preocupantes, uma vez que estão bem acima do permitido pela legislação vigente (até $300 \mathrm{mil} \mathrm{UFC/mL)} \mathrm{(BRASIL,}$ 2011), mostrando que maior atenção deve ser dada a higiene no momento da ordenha, transporte e armazenagem do leite cru refrigerado.

Cuidados com a saúde do úbere das vacas devem ser tomados, para controlar a alta CCS, para que o leite obtido nas fazendas atenda as exigências dos laticínios, trazendo maiores rendimentos e qualidade na fabricação de produtos lácteos.

\section{CONCLUSÕES}

A contagem de células somáticas no leite cru resfriado está associada a uma menor CBT, indicando que a higiene é um fator de grande importância e deve ser considerado para a obtenção do leite de melhor qualidade.

Conclui-se que os resultados encontrados nesta pesquisa, como a CCS e CBT no leite cru refrigerado coletado, na região do sudeste goiano demonstram condições de higiene insatisfatórias e precárias na ordenha dos animais.

\section{REFERÊNCIAS BIBLIOGRÁFICAS}

\section{ALVES, C. Efeito de variações sazonais na qualidade do leite cru refrigerado de duas propriedades de Minas Gerais. 2006. 65f. Dissertação (Mestrado em Medicina Veterinária) - Universidade federal de Minas gerais, Belo Horizonte, 2006.}

BRASIL. Ministério da Agricultura, Pecuária e Abastecimento. Instrução Normativa $\mathrm{n}^{\circ}$ 62, de 29 de dezembro de 2011. Aprova o Regulamento Técnico de Produção, Identidade e Qualidade do Leite tipo A, o Regulamento Técnico de Identidade e Qualidade de Leite Cru Refrigerado, o Regulamento Técnico de Identidade e Qualidade de Leite Pasteurizado e o Regulamento Técnico da Coleta de Leite 
Cru Refrigerado e seu Transporte a Granel, em conformidade com os Anexos desta Instrução Normativa. Diário Oficial da República Federativa do Brasil, Brasília, 30 dez. 2011. Seção 1, p. 6.

BAGGIO, A. P; MONTANHINI, M. T. M. Qualidade de leite cru produzido na região do Norte Pioneiro do Paraná. Revista Brasileira de Higiene e Sanidade Animal, v. 08, n. 3, p. 173-184, 2014.

BUENO, V. F. F. et al. Influência da temperatura de armazenamento e do sistema de utilização do tanque de expansão sobre a qualidade microbiológica do leite cru. Higiene Alimentar, v. 18, n. 124, p. 62-67, 2005.

COELHO, K. O. et al. Efeito da contagem de células somáticas sobre o rendimento e a composição físico-química do queijo muçarela. Arquivo Brasileiro de Medicina Veterinária e Zootecnia, v. 66, n. 4, p. 1260 1268, 2014.

DURR, J. W. Como produzir leite de alta qualidade. Brasília: SENAR, 28p. 2005.

FERREIRA, D. F. Sistema de análise estatística para dados balanceados (SISVAR). Lavras: UFLA/DEX, 2000.

LINDMARK-MANSSON, H., FONDÉN, R., PETTERSON, H. E. Composition of Swedish dairy milk. International Dairy Journal, v. 13, n. 6, p. 409-425, 2003.

MARTINS, M. E. P. et al. Qualidade de leite cru produzido e armazenado em tanques de expansão no Estado de Goiás. Ciência Animal Brasileira, v. 9, n. 4, p. 1152-1158, 2008.

PEREIRA, A. R.; MOTA, R. A.; ALMEIDA, C. C. Efeito do nível de células somáticas sobre os constituintes do leite I - gordura e proteína. Brazilian Journal Veterinary Research and Animal Science, São Paulo, v. 36, n. 3, p. 429-433, 1999.

PONCE P. C; HERNÁNDEZ, R. Propriedades físico-químicas do leite e sua associação com transtornos metabólicos e alterações na glândula mamária. In: GONZÁLEZ, F. H. D.; DÜRR, J. W.; FONTANELI, R. S. Uso do leite para monitorar a nutrição e o metabolismo de vacas leiteiras. Porto Alegre: Universidade Federal do Rio Grande do Sul, 2001. p. 61-72.

RAMIRES, C. H.; BERGER, E. L.; ALMEIDA, R. Influência da qualidade microbiológica da água sobre a qualidade do leite. Archives of Veterinary Science, v. 14, n. 1, p. 36-42, 2009.

RODRIGUES, M. Impacto da utilização da somatotropina bovina (bST) sobre a produção de leite e a avaliação genética de bovinos da raça Holandesa. 2008. $59 \mathrm{f}$. Dissertação (Mestrado em Ciências Biológicas) - Faculdade de Medicina de Ribeirão Preto da Universidade de São Paulo, São Paulo, 2008.

ROSA, D. C. et al. Qualidade do leite em amostras individuais e de tanque de vacas leiteiras. Arquivos do Instituto Biológico, v. 79, n. 4, p. 485-493, 2012.

SANTOS, P. A. et al. Qualidade do leite cru refrigerado estocado por diferentes períodos. Revista do Instituto de Laticínios Cândido Tostes, v. 63, n. 364, p. 36-41, dez. 2013.

SCHÄELLIBAUM, M. Efeitos de altas contagens de células somáticas sobre a produção e qualidade de queijos. In: SIMPÓSIO INTERNACIONAL SOBRE QUALIDADE DO LEITE: 2., 2000, Curitiba, PR. Anais... Curitiba: CIETEP/FIEP, 2000, p. 21-26. 